Editorial Office Notes:

RES-16-402.R2

ORIGINAL ARTICLE

Received 31 May 2016

Invited to revise 14 July and 6 September 2016

Revised 28 July and 21 September 2016

Accepted 24 September 2016

Associate Editor: Claire Wainwright 


\section{Physiological Markers of Exercise Capacity and Lung Disease Severity in Cystic}

\section{Fibrosis}

Laurie Smith ${ }^{1}$ MSc, Charles C Reilly ${ }^{1,2}$ PhD, Victoria MacBean ${ }^{1} \mathrm{PhD}$, Caroline J Jolley $\mathrm{y}^{1.3}$ PhD, Caroline Elston ${ }^{2}$ MBBS, John Moxham ${ }^{1}$ MD \& Gerrard F Rafferty ${ }^{1}$ PhD

${ }^{1}$ King's College London, Division of Asthma, Allergy and Lung Biology, London UK.

${ }^{2}$ King's College Hospital NHS Foundation Trust, London UK.

${ }^{3}$ King's College London, Centre for Human and Aerospace Physiological Sciences.

\section{Correspondence:}

Dr Gerrard Rafferty

Department of Respiratory Medicine (Chest Unit), $2^{\text {nd }}$ Floor Cheyne Wing, King's College Hospital, Denmark Hill, London SE5 9RS, UK

Email gerrard.rafferty@kcl.ac.uk

\section{Summary at a glance}

A novel marker of cystic fibrosis (CF) lung disease severity, inspiratory muscle electromyogram activity was investigated in 20 adult CF patients. Both $\mathrm{T}_{\mathrm{L}} \mathrm{CO}$ \%predicted and inspiratory muscle electromyogram activity related strongly to exercise performance and therefore may be useful in CF lung disease management. 


\section{ABSTRACT}

\section{Background and objective}

Peak aerobic capacity ( $\mathrm{VO}_{2}$ peak) is an important outcome measure in cystic fibrosis (CF) but measurement is not widely available and can be influenced by patient motivation, pain and fatigue. Alternative markers of disease severity would be helpful. Neural respiratory drive, measured using parasternal intercostal muscle electromyography (EMGpara) reflects the load to capacity balance of the respiratory system and provides a composite measure of pulmonary function impairment in CF. The aim of the study was to investigate the relationship between exercise capacity, EMGpara and established measures of pulmonary function in clinically stable adult CF patients.

\section{Methods}

Twenty CF patients (12 male, median (range) age 22.3 (17.0-43.1) years) performed the $10 \mathrm{~m}$ incremental shuttle walk test (ISWT) with contemporaneous measures of aerobic metabolism. EMGpara was recorded from second intercostal space at rest and normalised using the peak EMG obtained during maximum respiratory manoeuvres and expressed as EMGpara\%max.

\section{Results}

$\mathrm{VO}_{2}$ peak was strongly correlated with ISWT distance $(r=0.864, p<0.0001)$. $\mathrm{T}_{\mathrm{L}} \mathrm{CO}$ \%predicted was best correlated with $\mathrm{VO}_{2}$ peak $(r=0.842, p<0.0001)$ and ISWT distance $(r=0.788, p<0.0001)$. EMGpara\%max also correlated with $\mathrm{VO}_{2}$ peak $(-0.757, p<0.0001)$, while the relationships between exercise outcome measures and FEV ${ }_{1} \%$ predicted and FVC \%predicted were less strong. A $T_{L}$ CO \%predicted of $<70.5 \%$ was the strongest predictor of $\mathrm{VO}_{2}$ peak $<32 \mathrm{ml} / \mathrm{min} / \mathrm{kg}$, (AUC $0.96,100 \%$ sensitivity, $83.3 \%$ specificity). 
ISWT distance and EMGpara\%max also performed well, with other pulmonary function variables demonstrating poorer predictive ability.

\section{Conclusion}

$\mathrm{T}_{\llcorner} \mathrm{CO} \%$ predicted and $\mathrm{EMGpara \% max}$ relate strongly to exercise performance markers in CF and may provide alternative predictors of lung disease progression.

Keywords: cystic fibrosis, disease management, electromyography, exercise, intercostal muscles, respiratory function

Short title: Disease severity in Cystic Fibrosis 


\section{INTRODUCTION}

Forced expiratory volume in one second $\left(\mathrm{FEV}_{1}\right)$ and the rate of its decline are the most commonly used clinical predictors of survival in cystic fibrosis $(C F)^{1-3}$. FEV ${ }_{1}$ is, however, effort and technique dependent, relatively insensitive to small treatment responses ${ }^{4}$ and poorly related to symptoms ${ }^{5}$. Recent advances in CF care, have highlighted the prognostic insensitivity of $\mathrm{FEV}_{1}{ }^{6}$. Lung clearance index $(\mathrm{LCl})$ is more sensitive to changes in $\mathrm{CF}$ lung disease severity than $\mathrm{FEV}_{1}{ }^{7}$, but measurement remains limited primarily to the research setting.

The significant load imposed on the cardiovascular and respiratory systems during exercise testing can reveal pathophysiological changes associated with disease progression that are not detected using spirometry. Peak aerobic capacity $\left(\mathrm{VO}_{2 \text { peak }}\right)$ is related to quality of life $^{8}$, and is a strong predictor of hospitalisation ${ }^{9}$ and mortality ${ }^{10,11}$ in adult CF patients. Exercise testing, however, not only requires specialist equipment and personnel, but also significant patient motivation. Some individuals are unable to exercise maximally due to pain and fatigue.

Indices which reflect both the airways obstruction and lung hyperinflation that occur in CF lung disease may provide more accurate markers of disease severity. Measurement of neural respiratory drive (NRD), obtained during resting tidal breathing using the parasternal intercostal electromyogram (EMGpara), has been shown to provide a sensitive, easily applied indicator of load on the respiratory system that reflects lung disease severity in $\mathrm{CF}^{12,13}$. We wished, therefore, to test the hypothesis that indices 
which reflect the overall impact of the pathophysiological changes that occur in CF lung disease would most strongly relate to exercise performance as assessed by the $10 \mathrm{~m}$ incremental shuttle walk test (ISWT), in clinically stable adult CF patients and could, therefore, provide more robust markers of disease severity in CF.

\section{METHODS}

Clinically stable adult CF patients were recruited from Kings College Hospital, London, between January-July 2014. The study received local research ethics committee approval (South London (Dulwich) LREC Ref No 05/Q0703/82) and written informed consent was obtained.

\section{Measurements}

Spirometry, lung gas transfer $\left(\mathrm{T}_{\mathrm{L}} \mathrm{CO}\right)$ and its components (transfer coefficient $(\mathrm{KCO})$ and alveolar volume (Va)) and lung volumes using body plethysmography were measured (Jaeger Masterscreen, CareFusion, Germany). Height and weight were measured and body mass index (BMI) calculated. Fat free mass (FFM) was determined by bioelectrical impedance (Bodystat 1500, Bodystat Ltd., Isle of Man, UK). 
Surface EMGpara was recorded from the second intercostal space as previously described ${ }^{12}$. Resting EMGpara was measured during five minutes of relaxed breathing and the average value per breath calculated from the final minute. EMGpara was expressed as a percentage of the maximum value (EMGpara\%max) achieved during a maximal volitional inspiratory manoeuvre. Three manoeuvres were performed at least five times; inhalation to total lung capacity (TLC) from functional residual capacity (FRC), maximal inspiratory pressure (PImax) and maximal sniff nasal pressure (SNIP). Maximal pressures were recorded for Pimax and SNIP. The greatest peak EMGpara regardless of the manoeuvre performed was selected to normalise EMGpara ${ }^{12,14}$. For more details, see Supplementary Appendix S1.

Exercise capacity was assessed using the incremental shuttle walking test (ISWT) as previously described ${ }^{15}$ with the distance achieved recorded. During the ISWT, ventilatory and metabolic variables were measured using a portable exercise system (Metamax 3b, Cortex Medical, Germany) and oxygen saturation recorded using pulse oximetry.

\section{Protocol}

All measurements were made during a single visit. EMGpara was measured initially followed by the maximal inspiratory manoeuvres, then pulmonary function followed by the ISWT. 


\section{Data analysis}

All data expressed as median (range). Relationships between variables were assessed using Spearman correlation analysis. Change from rest to end exercise assessed using Wilcoxon matched pairs signed rank test. Mann-Whitney was used to compare variables between patients with $\mathrm{VVO}_{2}$ peak $>32 \mathrm{ml} / \mathrm{min} / \mathrm{kg}$ to those with a $\mathrm{VO}_{2}$ peak $<32 \mathrm{ml} / \mathrm{min} / \mathrm{kg}$. Receiver operator characteristic (ROC) analysis was used to evaluate the predictive power of variables with respect to $\mathrm{VO}_{2}$ peak $<32 \mathrm{ml} / \mathrm{min} / \mathrm{kg}$, using thresholds demonstrating optimum balance between sensitivity and specificity. Statistical analysis performed using Prism version 6.0 (GraphPad Software Inc., California, USA). A p value $<0.05$ was considered statistically significant, except for correlation analysis for which a $p$ value $<0.01$ was used to allow for the number of comparisons performed.

Mean (SD) EMGpara\%max was 13.4 (7) in 15 patients with $\mathrm{CF}^{12}$. Studying 20 patients would provide a representative sample with a $5 \%$ margin of error at the $10 \%$ level. 


\section{RESULTS}

Twenty adult patients, median (range) age 22.3 (17.0 - 43.1) years (12 male), with stable CF were studied (Table 1). The patients had a range of disease severity as classified using $\mathrm{FEV}_{1}$ z-score. Five had mild (median (range) $\mathrm{FEV}_{1}$ \%predicted 95.2\% (89.7 - 101.3)), three moderate (median (range) $\mathrm{FEV}_{1}$ \%predicted $66.2 \%(65.0-68.8)$ ), two severe (median (range) $\mathrm{FEV}_{1}$ \%predicted $55.0 \%(48.3-61.6)$ ) and 10 very severe airflow obstruction (median (range) $\mathrm{FEV}_{1}$ \%predicted $38.1 \%(16-50.3)$ ). Gas trapping and hyperinflation were also present as indicated by RV/TLC $>25 \%$ and TGV/TLC $>50 \%$ (Table 1).

All patients performed a maximal shuttle walk test as indicated by either a respiratory exchange ratio (RER) $>1.1(n=14)$, a max HR $>80 \%$ predicted $(n=4)$ or a maximum minute ventilation (Vemax) $>80 \%$ predicted (Predicted from $\left.\mathrm{FEV}_{1} \times 40\right)(\mathrm{n}=2)$. Median (range) ISWT distance was $645 \mathrm{~m}$ (280 - 880). All physiological variables changed significantly from baseline to end exercise (Table 2$)(p<0.001)$.

Median (range) $\mathrm{VO}_{2}$ peak $\left.23.9 \mathrm{ml} / \mathrm{min} / \mathrm{kg}(16.8-38.7)\right)$ and $\mathrm{VO}_{2}$ at $\mathrm{AT}(15.2 \mathrm{ml} / \mathrm{min} / \mathrm{kg}$ $(10.3-29.5))$ indicated markedly reduced exercise capacity in this patient group overall. A strong correlation was observed between ISWT distance and $\mathrm{VO}_{2}$ peak $(r=0.864$, $\mathrm{p}<0.0001)$. The relationship between $\mathrm{VO}_{2}$ peak and ISWT distance was described by the regression equation and $95 \%$ confidence intervals $\mathrm{VO}_{2}$ peak $=1.789(-4.91$ to 8.49$)+$ 0.0401 (0.03 to 0.05$) \times$ ISWT distance (Fig 1). 
EMGpara\%max reflected CF lung disease severity and was significantly correlated with $\mathrm{T}_{\mathrm{L}} \mathrm{CO}$ \%predicted, RV/TLC, $\mathrm{FEV}_{1} \%$ predicted and FVC \% predicted and Va \%predicted (Table 3).

$\mathrm{T}_{L} \mathrm{CO}$ \%predicted showed the strongest relationship with exercise outcome measures, correlating significantly with $\mathrm{VO}_{2}$ peak $(r=0.842, p<0.0001), \mathrm{VO}_{2}$ at AT $(r=0.671$, $p=0.0012)$ and ISWT distance $(r=0.788, p<0.0001)$ (Table 4). TLCO \%predicted showed the best correlation with end exercise $\mathrm{SpO}_{2}(r=0.64, \mathrm{p}<0.01)$. EMGpara\%max was also significantly correlated with $\mathrm{VO}_{2}$ peak, $\mathrm{VO}_{2}$ at AT and ISWT distance walked (Table 4). The relationships between exercise capacity and other lung function and respiratory muscle parameters including $\mathrm{FEV}_{1} \%$ predicted and FVC \%predicted were less strong (Table 4). Fat free mass correlated with ISWT distance.

Using the variables that correlated with $\mathrm{VO}_{2}$ peak, patients with a $\mathrm{VO}_{2}$ peak $<32 \mathrm{ml} / \mathrm{min} / \mathrm{kg}$ had significantly higher EMGpara\%max at rest and lower $\mathrm{T}_{L} \mathrm{CO}$ \%predicted, ISWT distance and FVC \%predicted than those with $\mathrm{VO}_{2}$ peak $>32 \mathrm{ml} / \mathrm{min} / \mathrm{kg}$ (Fig 2). Thresholds for predicting $\mathrm{VO}_{2}$ peak $<32 \mathrm{ml} / \mathrm{min} / \mathrm{kg}$, together with sensitivity and specificity values and area under the ROC curve for each measured variable are shown in Table 5. A $\mathrm{T}_{\mathrm{L}} \mathrm{CO} \%$ predicted of $<70.5 \%$ was the strongest predictor of $\mathrm{VO}_{2}$ peak $<32 \mathrm{ml} / \mathrm{min} / \mathrm{kg}$, (AUC 0.96, 100\% sensitivity, 83.3\% specificity). ISWT and EMGpara\%max also performed well, with other variables demonstrating poorer predictive ability (Table $5)$. 


\section{DISCUSSION}

The study examined the relationship between exercise capacity, EMGpara activity and pulmonary function in adult CF patients. EMGpara\%max and $\mathrm{T}_{\mathrm{L}} \mathrm{CO} \%$ predicted were more strongly related to measures of exercise performance than $\mathrm{FEV}_{1} . \mathrm{T}_{\mathrm{L}} \mathrm{CO}$ \%predicted was most strongly related to $\mathrm{VO}_{2}$ peak and ISWT distance and most accurately predicted $\mathrm{VO}_{2}$ peak.

Exercise capacity was assessed using the ISWT with contemporaneous measurements of respiratory and metabolic variables. The ISWT has been shown to provide a valid assessment of maximal exercise capacity in individuals with chronic respiratory diseases ${ }^{16,17}$. Patients performed the ISWT maximally and each test was conducted by an experienced practitioner. Although the ISWT was performed once only, all participants were accustomed to the test as part of their routine clinical assessment. Contemporaneous measurement of metabolic variables avoided comparison between results of exercise tests performed on two separate occasions. Exercise limitation in CF is multifactorial hence not all patients will demonstrate respiratory limitation at end exercise, however each patient was deemed to have reached limitation by at least one of the described criteria: RER >1.1 representing metabolic limitation, HR $>80 \%$ predicted representing cardiac limitation or Vemax $>80 \%$ predicted representing ventilatory limitation. 
To reduce contamination from adjacent postural muscles and ensure good quality EMGpara signals were acquired, patients adopted a relaxed seated position with arms supported and adaptive mains filtering and post-acquisition digital band-pass filtering were applied to minimise background electrical noise. Standardised electrode position and good electrical contact were adopted to minimise poor between-subject and between-occasion reproducibility ${ }^{18}$. EMG signal attenuation due to subcutaneous fat was not considered important as none of the patients were obese.

As expected, a strong correlation between ISWT distance and $\mathrm{VO}_{2}$ peak was observed and the data broadly comparable to those obtained by Bradley et al ${ }^{19}(r=0.95, p<0.01)$ using a modified ISWT ${ }^{19}$. When compared in percentage terms to these data ${ }^{19}$, the steeper slope and lower intercept of the regression equation derived from the current data resulted in slightly lower values for $\mathrm{VO}_{2}$ peak at the shorter ISWT distances $(90 \%$ at $300 \mathrm{~m})$ and higher values at the longer ISWT distances $(118 \%$ at $900 \mathrm{~m})$. These differences probably reflect the use of the modified ISWT by Bradley et al and the inclusion of patients with greater exercise tolerance and higher $\mathrm{VO}_{2}$ peak.

Measures of exercise capacity were also strongly correlated with a number of pulmonary function variables and EMGpara\%max. Overall, $\mathrm{VO}_{2}$ peak, $\mathrm{VO}_{2}$ at $\mathrm{AT}$ and ISWT distance were most strongly correlated with $\mathrm{T}_{\mathrm{L}} \mathrm{CO} \%$ predicted. The strength of the relationship between $\mathrm{T}_{\mathrm{L}} \mathrm{CO} \%$ predicted and $\mathrm{VO}_{2}$ peak $(r=0.842)$ was similar to that observed between ISWT distance and $\mathrm{VO}_{2}$ peak $(r=0.864)$, suggesting $\mathrm{T}_{L} \mathrm{CO}$ could be a useful marker of lung disease severity in CF patients particularly in those that are unable 
or unwilling to exercise maximally. Similar, albeit less strong relationships were observed between EMGpara\%max, $\mathrm{VO}_{2}$ peak, $\mathrm{VO}_{2}$ at AT and ISWT distance. Interestingly $\mathrm{FEV}_{1}$ and $\mathrm{RV} / \mathrm{TLC}$ were only moderately well correlated with markers of exercise capacity, reflecting previous findings on the strength of the relationships observed between pulmonary function and exercise performance ${ }^{6,19}$..

Pianosi et al demonstrated that a $\mathrm{VO}_{2}$ peak $<32 \mathrm{ml} / \mathrm{min} / \mathrm{kg}$ was associated with a $60 \%$ eight-year mortality in $\mathrm{CF}^{10}$. Our data indicated that patients with a $\mathrm{VO}_{2}$ peak $<32 \mathrm{ml} / \mathrm{min} / \mathrm{kg}$ had significantly lower levels of $\mathrm{T}_{\mathrm{L}} \mathrm{CO} \%$ predicted and higher levels of EMGpara\%max as well as decreased ISWT distance, FEV $_{1}$ \%predicted and FVC \%predicted. Receiver operator curve analysis indicated $\mathrm{T}_{\mathrm{L}} \mathrm{CO} \%$ predicted $<70.2 \%$ was the strongest predictor of a $\mathrm{VO}_{2}$ peak $<32 \mathrm{ml} / \mathrm{min} / \mathrm{kg}$. Both ISWT distance and EMGpara\%max also had good positive predictive accuracy, while FVC \%predicted and $\mathrm{FEV}_{1} \%$ predicted performed less well. The relatively poorer predictive capacity of spirometric variables was most likely due to such measures only representing one aspect of the pathophysiological changes that occur in CF lung disease and hence do not fully reflect the range of factors which limit exercise in this patient group.

There are few data available concerning the relationship between exercise performance and $\mathrm{T}_{L} \mathrm{CO}$ in CF. Pastre et $\mathrm{a}^{20}$ demonstrated that $\mathrm{T}_{L} \mathrm{CO}$ and $\mathrm{FEV}_{1}$ correlated with $\mathrm{VO}_{2}$ peak, but that $\mathrm{FEV}_{1}$ demonstrated the strongest relationship. The study did, however, involve bootstrapping to account for missing data for some variables including 
$T_{L}$ CO. Our results are similar in that $\mathrm{FEV}_{1}$ did correlate with $\mathrm{VO}_{2}$ peak, but that $T_{L} C O$ \%predicted had the strongest relationship.

Exercise tolerance in CF is multifactorial, only $30 \%$ of the variability in exercise performance has been attributed to airways obstruction ${ }^{20-23}$. Gas exchange abnormalities have also been shown to affect exercise performance ${ }^{24-26}$. Small airway dysfunction leading to ventilation heterogeneity and ventilation perfusion mismatch alongside elevated venous admixture, intrapulmonary shunting and alveolar hypoventilation ${ }^{7,27,28}$ have been implicated. $\mathrm{T}_{\mathrm{L}} \mathrm{CO}$ reflects the lung volume available for gas exchange, gas diffusion and exchange across the alveolar membrane. In worsening CF lung disease, accessible alveolar volume decreases due to ventilation heterogeneity and gas diffusion is impaired by suboptimal ventilation/perfusion relationships. By contrast gas exchange across the alveolar membrane is not substantially reduced, as demonstrated in the current cohort by the relatively well preserved KCO. When considered alongside the measured reductions in alveolar volume and the relationship of $\mathrm{Va}$ \%predicted to $\mathrm{VO}_{2}$ peak and $\mathrm{VO}_{2}$ at $\mathrm{AT}$ and the relationship between $\mathrm{TLCO} \%$ predicted and end exercise $\mathrm{SpO}_{2}$, the current data suggest that it is the decreased accessible lung volume and impaired gas diffusion as measured using $\mathrm{T}_{\mathrm{L}} \mathrm{CO}$ that contributed mostly to exercise impairment in this cohort of CF patients rather than airways obstruction.

The parasternal intercostal muscles are obligate inspiratory muscles recruited in tandem with the diaphragm, acting to prevent rib cage distortion and ventilatory 
inefficiency. EMGpara increases progressively alongside diaphragm EMG during exercise $^{12}$. EMGpara provides a measure of NRD which, unlike measures such as spirometry which only measures a single aspect of respiratory function, reflects the combined effects of mechanical and metabolic load on the respiratory system. In CF, airways obstruction and lung hyperinflation increase the load on the respiratory muscles. Lung hyperinflation increases the elastic work of breathing and the development of intrinsic positive end-expiratory pressure which imposes a threshold load on each breath. Hyperinflation also reduces inspiratory muscle length leading to functional inspiratory muscle weakness ${ }^{29}$. NRD as measured by EMGpara increases to maintain ventilation at the appropriate level for blood gas homeostasis. The current data confirm our previous findings that EMGpara\%max provides a sensitive indicator of load on the respiratory system which is related to disease severity in $\mathrm{CF}^{12,13}$ and demonstrate that this index provides an effort independent measure of exercise capacity which could be helpful in disease management.

EMGpara\%max and $T_{L} C O$ \%predicted were also strongly correlated with each other. As median KCO \%predicted for the group was $99 \%$ and not significantly related to EMGpara\%max, the current data suggest that the significant relationship between $\mathrm{T}_{\mathrm{L}} \mathrm{CO} \%$ predicted and EMGpara\%max was primarily due to decrements in alveolar volume available for gas exchange. A significant correlation between EMGpara\%max and Va \%predicted was observed. 
Although exercise limitation in CF has a large ventilatory component, it is also influenced by peripheral muscle function ${ }^{30-32}$ and nutritional status ${ }^{21}$ as indicated by the significant correlation between FFM and ISWT distance. Suboptimal peripheral muscle function results in decreased aerobic metabolism and early lactic acidaemia ${ }^{23,31}$, resulting in reduced exercise capacity. Although $\mathrm{T}_{\mathrm{L}} \mathrm{CO}$ and EMGpara\%max were strongly correlated with physiological measures of exercise capacity, such measurements were performed at rest and therefore do not reflect both the influence of peripheral muscle dysfunction and the changes in lung function such as dynamic hyperinflation ${ }^{12}$ that occur during exercise which influence exercise performance.

$\mathrm{T}_{L} \mathrm{CO}$ is not routinely measured in CF and is not part of CF care standards ${ }^{33}$. There is conflicting evidence as to the benefit of measuring $T_{L} C O$ in patients with $C F$. $T_{L} C O$ has been shown to be maintained until lung disease becomes more advanced ${ }^{34}$ and hence is unhelpful prognostically ${ }^{35}$. Conversely, serial measurements have been shown to correlate with clinical severity in patients with advanced lung disease, unlike routine lung function tests such as $\mathrm{FEV}_{1}{ }^{36,37}$. Although lung function indices such as $\mathrm{FEV}_{1}$ and FVC are commonly used to assess CF lung disease severity, assessment of exercise performance is a key clinical and trial outcome tool in CF ${ }^{33,38}$ and measurement of $\mathrm{VO}_{2}$ peak has been shown to better predict both mortality ${ }^{10,11,39}$ and the risk of hospitalisation ${ }^{9}$. Exercise testing with the aim of measuring $\mathrm{VO}_{2}$ peak is, however, expensive and demanding on patients and therefore not always utilised in CF centres. This study has shown that measurements of $\mathrm{T}_{L} \mathrm{CO}$ \%predicted, as well EMGpara\%max were strongly related to exercise performance. 
In conclusion, measurement of peak aerobic capacity is an important assessment tool in CF management. It is, however, not widely available and such testing can be negatively influenced by poor patient motivation, pain, fatigue as well as shortness of breath. Integrated measures of pulmonary function such as $\mathrm{T}_{\mathrm{L}} \mathrm{CO}$ \%predicted and EMGpara\%max were related strongly to exercise performance in adult patients with CF and therefore may be of benefit in the assessment of CF lung disease severity. 


\section{Acknowledgements}

LS was supported by National Institute of Health Research (UK) grant 


\section{REFERENCES}

1 Block JK, Vandemheen KL, Tullis E, Fergusson D, Doucette $S$, Haase D, Berthiaume Y, Brown N, Wilcox P, Bye P, Bell S, Noseworthy M, Pedder L, Freitag A, Paterson N, Aaron SD. Predictors of pulmonary exacerbations in patients with cystic fibrosis infected with multi-resistant bacteria. Thorax. 2006; 61: 969-74.

2 Corey M, Farewell V. Determinants of mortality from cystic fibrosis in Canada, 1970-1989. Am J Epidemiol. 1996; 143: 1007-17.

3 Milla CE, Warwick WJ. Risk of death in cystic fibrosis patients with severely compromised lung function. Chest. 1998; 113: 1230-4.

4 Que C, Cullinan P, Geddes D. Improving rate of decline of FEV1 in young adults with cystic fibrosis. Thorax. 2006; 61: 155-7.

5 de Jong W, van der Schans CP, Mannes GP, van Aalderen WM, Grevink RG, Koeter $\mathrm{GH}$. Relationship between dyspnoea, pulmonary function and exercise capacity in patients with cystic fibrosis. Respir Med. 1997; 91: 41-6.

6 George PM, Banya W, Pareek N, Bilton D, Cullinan P, Hodson ME, Simmonds NJ. Improved survival at low lung function in cystic fibrosis: cohort study from 1990 to 2007. BMJ. 2011; 342: d1008.

7 Kraemer R, Blum A, Schibler A, Ammann RA, Gallati S. Ventilation inhomogeneities in relation to standard lung function in patients with cystic fibrosis. Am J Respir Crit Care Med. 2005; 171: 371-8.

8 de Jong W, Kaptein AA, van der Schans CP, Mannes GP, van Aalderen WM, Grevink RG, Koeter GH. Quality of life in patients with cystic fibrosis. Pediatr Pulmonol. 1997; 23: 95-100.

9 Perez M, Groeneveld IF, Santana-Sosa E, Fiuza-Luces C, Gonzalez-Saiz L, VillaAsensi JR, Lopez-Mojares LM, Rubio M, Lucia A. Aerobic fitness is associated with lower risk of hospitalization in children with cystic fibrosis. Pediatr Pulmonol. 2014; 49: 641-9. 10 Pianosi P, Leblanc J, Almudevar A. Peak oxygen uptake and mortality in children with cystic fibrosis. Thorax. 2005; 60: 50-4.

11 Nixon PA, Orenstein DM, Kelsey SF, Doershuk CF. The prognostic value of exercise testing in patients with cystic fibrosis. N Engl J Med. 1992; 327: 1785-8.

12 Reilly CC, Ward K, Jolley CJ, Lunt AC, Steier J, Elston C, Polkey MI, Rafferty GF, Moxham J. Neural respiratory drive, pulmonary mechanics and breathlessness in patients with cystic fibrosis. Thorax. 2011; 66: 240-6.

13 Reilly CC, Jolley CJ, Elston C, Moxham J, Rafferty GF. Measurement of parasternal intercostal EMG during an infective exacerbation in patients with Cystic Fibrosis. Eur Respir J. 2012.

14 Jolley CJ, Luo YM, Steier J, Reilly C, Seymour J, Lunt A, Ward K, Rafferty GF, Polkey $\mathrm{MI}$, Moxham J. Neural respiratory drive in healthy subjects and in COPD. Eur Respir J. 2009; 33: 289-97.

15 Singh SJ, Morgan MD, Scott S, Walters D, Hardman AE. Development of a shuttle walking test of disability in patients with chronic airways obstruction. Thorax. 1992; 47: 1019-24. 
16 Hill K, Dolmage TE, Woon L, Coutts D, Goldstein R, Brooks D. Comparing peak and submaximal cardiorespiratory responses during field walking tests with incremental cycle ergometry in COPD. Respirology. 2012; 17: 278-84.

17 Parreira VF, Janaudis-Ferreira T, Evans RA, Mathur S, Goldstein RS, Brooks D. Measurement properties of the incremental shuttle walk test. a systematic review. Chest. 2014; 145: 1357-69.

18 Luo YM, Moxham J, Polkey MI. Diaphragm electromyography using an oesophageal catheter: current concepts. Clinical Science. 2008; 115: 233-44.

19 Bradley J, Howard J, Wallace E, Elborn S. Validity of a modified shuttle test in adult cystic fibrosis. Thorax. 1999; 54: 437-9.

20 Pastre J, Prevotat A, Tardif C, Langlois C, Duhamel A, Wallaert B. Determinants of exercise capacity in cystic fibrosis patients with mild-to-moderate lung disease. BMC Pulm Med. 2014; 14: 74.

21 Marcotte JE, Grisdale RK, Levison H, Coates AL, Canny GJ. Multiple factors limit exercise capacity in cystic fibrosis. Pediatr Pulmonol. 1986; 2: 274-81.

22 Lands LC, Heigenhauser GJ, Jones NL. Analysis of factors limiting maximal exercise performance in cystic fibrosis. Clin Sci (Lond). 1992; 83: 391-7.

23 Shah AR, Gozal D, Keens TG. Determinants of aerobic and anaerobic exercise performance in cystic fibrosis. Am J Respir Crit Care Med. 1998; 157: 1145-50.

24 Bradley S, Solin P, Wilson J, Johns D, Walters EH, Naughton MT. Hypoxemia and hypercapnia during exercise and sleep in patients with cystic fibrosis. Chest. 1999; 116: 647-54.

25 McKone EF, Barry SC, Fitzgerald MX, Gallagher CG. Role of arterial hypoxemia and pulmonary mechanics in exercise limitation in adults with cystic fibrosis. J Appl Physiol (1985). 2005; 99: 1012-8.

26 Marcus $\mathrm{CL}$, Bader D, Stabile MW, Wang $\mathrm{Cl}$, Osher AB, Keens TG. Supplemental oxygen and exercise performance in patients with cystic fibrosis with severe pulmonary disease. Chest. 1992; 101: 52-7.

27 Dantzker DR, Patten GA, Bower JS. Gas exchange at rest and during exercise in adults with cystic fibrosis. Am Rev Respir Dis. 1982; 125: 400-5.

28 Cropp GJ, Pullano TP, Cerny FJ, Nathanson IT. Exercise tolerance and cardiorespiratory adjustments at peak work capacity in cystic fibrosis. Am Rev Respir Dis. 1982; 126: 211-6.

29 Polkey MI, Hamnegard CH, Hughes PD, Rafferty GF, Green M, Moxham J. Influence of acute lung volume change on contractile properties of human diaphragm. Journal of Applied Physiology: Respiratory, Environmental \& Exercise Physiology. 1998; 85: $1322-8$.

30 Selvadurai HC, Allen J, Sachinwalla T, Macauley J, Blimkie CJ, Van Asperen PP. Muscle function and resting energy expenditure in female athletes with cystic fibrosis. Am J Respir Crit Care Med. 2003; 168: 1476-80.

31 Moser C, Tirakitsoontorn P, Nussbaum E, Newcomb R, Cooper DM. Muscle size and cardiorespiratory response to exercise in cystic fibrosis. Am J Respir Crit Care Med. 2000; 162: 1823-7.

32 de Meer K, Gulmans VA, van Der Laag J. Peripheral muscle weakness and exercise capacity in children with cystic fibrosis. Am J Respir Crit Care Med. 1999; 159: 748-54. 
33 Conway S, Balfour-Lynn IM, De Rijcke K, Drevinek P, Foweraker J, Havermans T, Heijerman H, Lannefors L, Lindblad A, Macek M, Madge S, Moran M, Morrison L, Morton A, Noordhoek J, Sands D, Vertommen A, Peckham D. European Cystic Fibrosis Society Standards of Care: Framework for the Cystic Fibrosis Centre. J Cyst Fibros. 2014; 13 Suppl 1: S3-22.

34 Merkus PJ, Govaere ES, Hop WH, Stam H, Tiddens HA, de Jongste JC. Preserved diffusion capacity in children with cystic fibrosis. Pediatr Pulmonol. 2004; 37: 56-60.

35 Rosenthal M. Annual assessment spirometry, plethysmography, and gas transfer in cystic fibrosis: do they predict death or transplantation. Pediatr Pulmonol. 2008; 43: 945-52.

36 Russell NJ, Bagg LR, Hughes DT, Neville E. Lung function in young adults with cystic fibrosis. Br J Dis Chest. 1982; 76: 35-43.

37 Espiritu JD, Ruppel G, Shrestha Y, Kleinhenz ME. The diffusing capacity in adult cystic fibrosis. Respir Med. 2003; 97: 606-11.

38 Smyth AR, Bell SC, Bojcin S, Bryon M, Duff A, Flume P, Kashirskaya N, Munck A, Ratjen F, Schwarzenberg SJ, Sermet-Gaudelus I, Southern KW, Taccetti G, Ullrich G, Wolfe S, European Cystic Fibrosis S. European Cystic Fibrosis Society Standards of Care: Best Practice guidelines. J Cyst Fibros. 2014; 13 Suppl 1: S23-42.

39 Moorcroft AJ, Dodd ME, Webb AK. Exercise testing and prognosis in adult cystic fibrosis. Thorax. 1997; 52: 291-3. 
Table 1. Patient characteristics, pulmonary function and exercise performance in 20 adult patients with CF.

\begin{tabular}{|l|c|}
\hline & Median (range) \\
\hline Age (years) & $22.3(17.0-43.2)$ \\
\hline Height (cm) & $169.9(150.1-178.4)$ \\
\hline Weight (kg) & $19.9(18.0-27.2)$ \\
\hline BMI (kg/m $\left.{ }^{2}\right)$ & $80.0(59.4-91.9)$ \\
\hline FFM (\%) & $49.3(16.0-101.3)$ \\
\hline FEV ${ }_{1} \% p r e d i c t e d$ & $76.5(23.8-111.9)$ \\
\hline FVC \%predicted & $44.0(22.0-74.0)$ \\
\hline RV/TLC (\%) & $61.0(43.0-79.0)$ \\
\hline TGV/TLC (\%) & $70.5(41.1-104.1)$ \\
\hline TLCO \%predicted & $98.8(70.6-127.4)$ \\
\hline KCO \%predicted & $95.7(33.2-126.8)$ \\
\hline Va \%predicted & $94.0(40.61-128.6)$ \\
\hline Pimax (cm $\left.{ }_{2} O\right)$ & \\
\hline SNIP (cmH $\left.{ }_{2} \mathrm{O}\right)$ & \\
\hline & \\
\hline & \\
\hline & \\
\hline
\end{tabular}

BMI body mass index, FFM fat free mass, FEV1, forced expired volume in 1 second, FVC forced vital capacity, RV residual volume, TLC total lung capacity, TGV thoracic gas volume, $T_{L}$ CO lung gas transfer, KCO transfer coefficient, Va alveolar volume, Pimax maximal inspiratory pressure, SNIP sniff nasal inspiratory pressure) 
Table 2. Median (range) rest and end exercise data for ISWT, $\mathrm{VO}_{2}$ peak, $\mathrm{VCO}_{2}$ peak, RER, $\mathrm{Ve} / \mathrm{VO}_{2}, \mathrm{Ve} / \mathrm{VCO}_{2}$, Ve \%predicted, heart rate, $\mathrm{SpO}_{2}$ and $\mathrm{EMGpara} \% \max$.

\begin{tabular}{|c|c|c|c|}
\hline Variable & Resting & End Exercise & $p$ \\
\hline ISWT distance $(\mathrm{m})$ & & $645 \mathrm{~m}(280-880)$ & \\
\hline $\mathrm{VO}_{2}$ peak $(\mathrm{ml} / \mathrm{min} / \mathrm{kg})$ & $5.8(4.3-8.1)$ & $24.4(16.8-38.7)$ & $<0.001$ \\
\hline VCO ${ }_{2}$ peak $(\mathrm{ml} / \mathrm{min} / \mathrm{kg})$ & $4.7(3.1-7.1)$ & $24.9(14.1-42.5)$ & $<0.001$ \\
\hline $\mathrm{RER}$ & $0.83(0.62-0.94)$ & $1.09(0.8-1.46)$ & $<0.001$ \\
\hline $\mathrm{Ve} / \mathrm{VO}_{2}$ & & $35.15(25.1-45.6)$ & \\
\hline $\mathrm{Ve} / \mathrm{VCO}_{2}$ & & $32.7(24.6-48.8)$ & \\
\hline $\mathrm{Ve}(\% p r e d)$. & $12.0(4.9-41.9)$ & $63.7(43.0-114.0)$ & $<0.001$ \\
\hline $\mathrm{HR}(\mathrm{bpm})$ & $86.5(60-110)$ & $161(125-175)$ & $<0.001$ \\
\hline SpO & & $93(70-97)$ & $<0.001$ \\
\hline EMGpara\%max (\%) & $7.8(2.0-34.5)$ & & \\
\hline
\end{tabular}

ISWT incremental shuttle walk test, $\mathrm{VO}_{2}$ peak peak oxygen consumption, $\mathrm{VCO}_{2}$ peak peak carbon dioxide production, RER respiratory exchange ratio, Ve minute ventilation, HR heart rate, $\mathrm{SpO}_{2}$ pulse oximetry derived oxygen saturation, EMGpara\%max parasternal intercostal muscle EMG expressed as a percentage of maximum) 
Table 3. Spearman's correlation analysis examining the relationships between resting EMGpara\%max and $\mathrm{T}_{\mathrm{L}} \mathrm{CO} \%$ predicted, RV/TLC, FEV1 \% predicted, FVC \% predicted and Va \%predicted.

\begin{tabular}{|l|c|c|}
\hline & \multicolumn{2}{|l|}{ EMGpara\%max } \\
\hline & $r$ & $P$ \\
\hline TLCO \%predicted & -0.78 & $<0.0001$ \\
\hline RV/TLC \%predicted & 0.69 & 0.001 \\
\hline FEV 1 \%predicted & -0.65 & 0.002 \\
\hline Va \%predicted & -0.62 & 0.004 \\
\hline FVC \%predicted & -0.61 & 0.004 \\
\hline
\end{tabular}

$\mathrm{T}_{L} \mathrm{CO}$ lung gas transfer, RV residual volume, TLC total lung capacity, FEV1, forced expired volume in 1 second, Va alveolar volume, FVC forced vital capacity 
Table 4. Spearman's correlation analysis examining the relationships of $\mathrm{VO}_{2}$ peak, AT and ISWT distance with $\mathrm{T}_{\mathrm{L}} \mathrm{CO} \%$ predicted, resting EMGpara\%max, $\mathrm{FEV}_{1} \%$ predicted, FVC \%predicted and FFM.

\begin{tabular}{|c|c|c|c|c|c|c|}
\hline & \multicolumn{2}{|c|}{$\begin{array}{c}\mathrm{VO}_{2} \text { peak } \\
\text { (ml/min/kg) }\end{array}$} & \multicolumn{2}{|c|}{$\begin{array}{c}\mathrm{VO}_{2} \text { at } \mathrm{AT} \\
(\mathrm{ml} / \mathrm{min} / \mathrm{kg})\end{array}$} & \multicolumn{2}{|c|}{$\begin{array}{l}\text { ISWT Distance Walked } \\
\qquad(\mathrm{m})\end{array}$} \\
\hline & $r$ & $p$ & $r$ & $P$ & $r$ & $p$ \\
\hline $\mathrm{T}_{\mathrm{L}} \mathrm{CO} \%$ predicted & 0.842 & $<0.0001$ & 0.671 & 0.0012 & 0.788 & $<0.0001$ \\
\hline EMGpara\%max & -0.757 & $<0.0001$ & -0.669 & 0.0012 & -0.720 & $<0.0001$ \\
\hline FVC \%predicted & 0.593 & 0.0058 & 0.666 & 0.0013 & 0.551 & 0.011 \\
\hline $\mathrm{FEV}_{1} \%$ predicted & 0.558 & $0.011^{*}$ & 0.549 & $0.012 *$ & 0.581 & 0.007 \\
\hline Va \%predicted & 0.572 & 0.008 & 0.592 & 0.006 & 0.509 & $0.022^{*}$ \\
\hline FFM (\%) & 0.524 & $0.018 *$ & 0.295 & 0.207 & 0.628 & 0.003 \\
\hline
\end{tabular}

${ }^{*} p$ values less than 0.01 used to define significance due to the number of comparisons performed. $\mathrm{T}_{\mathrm{L}} \mathrm{CO}$ lung gas transfer, EMGpara\%max parasternal intercostal muscle EMG expressed as a percentage of maximum, FVC forced vital capacity, FEV1, forced expired volume in 1 second, Va alveolar volume, FFM fat free mass 
Table 5. Results of ROC analysis to predict $\mathrm{VO}_{2}$ peak $<32 \mathrm{ml} / \mathrm{min} / \mathrm{kg}$. Area under curve, sensitivity and specificity for $\mathrm{T}_{\mathrm{L}} \mathrm{CO}$ \%predicted, ISWT distance, EMGpara\%max, FVC \%predicted and FEV1 \%predicted.

\begin{tabular}{|l|c|c|c|c|}
\hline \multicolumn{1}{|c|}{ Variable } & Threshold & Area & Sensitivity & Specificity \\
\hline TLCO \%predicted & $<70.5 \%$ & 0.96 & 100 & 83.3 \\
\hline ISWT & $<670 \mathrm{~m}$ & 0.93 & 100 & 84.6 \\
\hline EMGpara\%max & $>10.20 \%$ & 0.92 & 100 & 76.9 \\
\hline FVC & $<77.7 \%$ & 0.87 & 85.71 & 76.9 \\
\hline FEV 1 \%predicted & $<63.30 \%$ & 0.86 & 85.71 & 84.6 \\
\hline Va \%predicted & $<70.15$ & 0.86 & 100 & 53.9 \\
\hline
\end{tabular}

TLCO lung gas transfer, ISWT incremental shuttle walk distance, EMGpara\%max parasternal intercostal muscle EMG expressed as a percentage of maximum, FVC forced vital capacity, FEV1, forced expired volume in 1 second, Va alveolar volume) 


\section{Figure legends}

Figure 1. Regression analysis describing the relationship between $\mathrm{VO}_{2}$ peak and ISWT distance. Dashed line lines represent 95\% confidence intervals. Regression equation $(95 \% \mathrm{Cl})$ VO2peak $=1.789(-4.91$ to 8.49$)+0.0401(0.03$ to 0.05$) \times$ ISWT distance

Figure 2. Comparison of EMGpara\%max, $\mathrm{T}_{L} \mathrm{CO}$, ISWT and FVC \%predicted and FEV1 \%predicted in patients achieving a VO2peak $<32 \mathrm{ml} / \mathrm{min} / \mathrm{kg}$ with those of $>32 \mathrm{ml} / \mathrm{min} / \mathrm{kg}$. Horizontal lines indicate median 